\title{
Investigation on Thermal Degradation Process of Polymer Solar Cells Based on Blend of PBDTTT-C and $\mathrm{PC}_{70} \mathrm{BM}$
}

\author{
Yu Ning, ${ }^{1}$ Longfeng Lv, ${ }^{1}$ Yunzhang Lu, ${ }^{1}$ Aiwei Tang, ${ }^{1,2}$ Yufeng Hu, ${ }^{1}$ Zhidong Lou, ${ }^{1}$ Feng \\ Teng, ${ }^{1}$ and Yanbing Hou ${ }^{1}$ \\ ${ }^{1}$ Key Laboratory of Luminescence and Optical Information, Beijing Jiaotong University, Ministry of Education, Beijing 100044, China \\ ${ }^{2}$ Department of Chemistry, School of Science, Beijing Jiaotong University, Beijing 100044, China
}

Correspondence should be addressed to Feng Teng; fteng@bjtu.edu.cn and Yanbing Hou; ybhou@bjtu.edu.cn

Received 30 March 2014; Revised 2 July 2014; Accepted 16 July 2014; Published 19 August 2014

Academic Editor: Juliusz Sworakowski

Copyright (C) 2014 Yu Ning et al. This is an open access article distributed under the Creative Commons Attribution License, which permits unrestricted use, distribution, and reproduction in any medium, provided the original work is properly cited.

The effects of thermal treatment on the photovoltaic performance of conventional and inverted polymer solar cells (PSCs) based on the combination of poly[(4,8-bis-(2-ethylhexyloxy)-benzo[1,2-b;4,5-b'] dithiophene)-2,6-diyl-alt-(4-(2-ethylhexanoyl)thie-no[3,4-b]thiophene))-2,6-diyl] (PBDTTT-C) and [6,6]-phenyl $\mathrm{C}_{70}$-butyric acid methyl ester $\left(\mathrm{PC}_{70} \mathrm{BM}\right)$ are investigated. The transient photoconductivity, the absorption spectra, and the transmission electron microscopy (TEM) images have been employed to study the thermal degradation of the inverted PSCs. The degradation is attributed to the inefficient charge generation and imbalance in charge-carrier transport, which is closely associated with the morphological evolution of the active layer with prolonged heating time.

\section{Introduction}

Bulk heterojunction (BHJ) PSCs have been paid much attention as candidates for sustainable solar energy converters because of their unique advantages of low cost, light weight, large area, and simple solution-based fabrication with mechanical flexibility. The power conversion efficiency (PCE) has been extensively enhanced using low-bandgap materials, optimizing the device structures and controlling the morphology of active layers [1-4]. Although the reported PCEs nearly meet the initial requirements for commercial applications, the poor stability of the PSCs is still a major barrier to realize the commercialization [5-8]. Improvements are necessary to enhance the stability of these devices.

Related studies have suggested decay mechanisms, such as the electrode degradation under the presence of oxygen and moisture [9], metal ion diffusion into the active layers from the electrodes [10], and photoactive material degradation with oxygen and moisture upon illumination and heating of the device [11-14]. Several groups have investigated the thermal degradation of PSCs by simulating the actual working environment under sunlight. For instance, Wong et al. reported that the microscopic and nanoscopic crystallization of $[6,6]$-phenyl $\mathrm{C}_{60}$-butyric acid methyl ester $\left(\mathrm{PC}_{60} \mathrm{BM}\right)$ influenced the morphological stability and performance of polymer-fullerene solar cells under thermal stress [15].

However, the mechanisms of PSC degradation under thermal stress, as well as the sustained morphological changes and charge transport kinetics, remain unclear. In this study, inverted and conventional PSCs based on the blend of PBDTTT-C and $\mathrm{PC}_{70} \mathrm{BM}$ were fabricated. The thermal stability and optoelectronic behavior of these devices were investigated via morphological analyses and transient photocurrent measurements.

\section{Experimental}

2.1. Materials. $\mathrm{ZnO}$ precursor was prepared by dissolving $0.3 \mathrm{~mol}$ zinc acetate dehydrate $\left(\mathrm{Zn}\left(\mathrm{OOCCH}_{3}\right)_{2} \cdot 2 \mathrm{H}_{2} \mathrm{O}\right.$, ACS, 


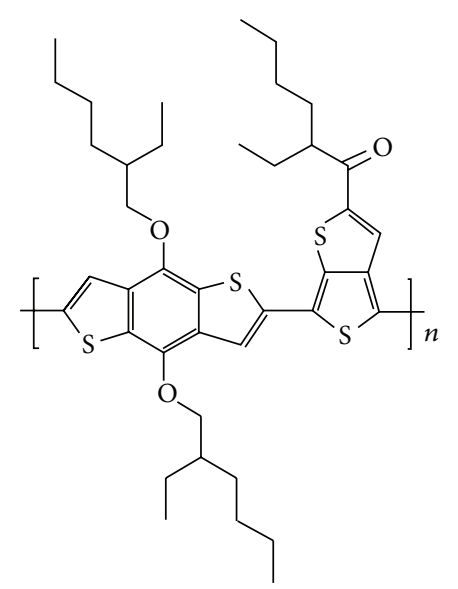

PBDTTT-C

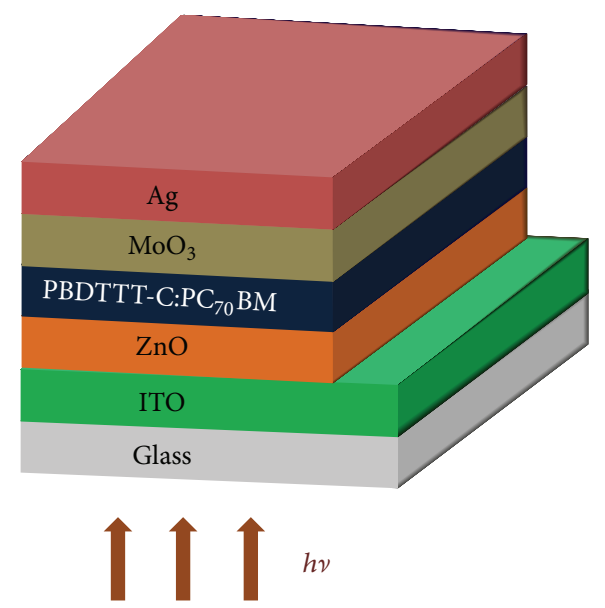

(b)

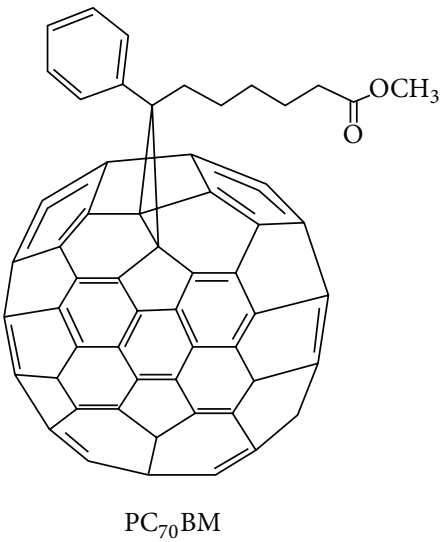

(a)

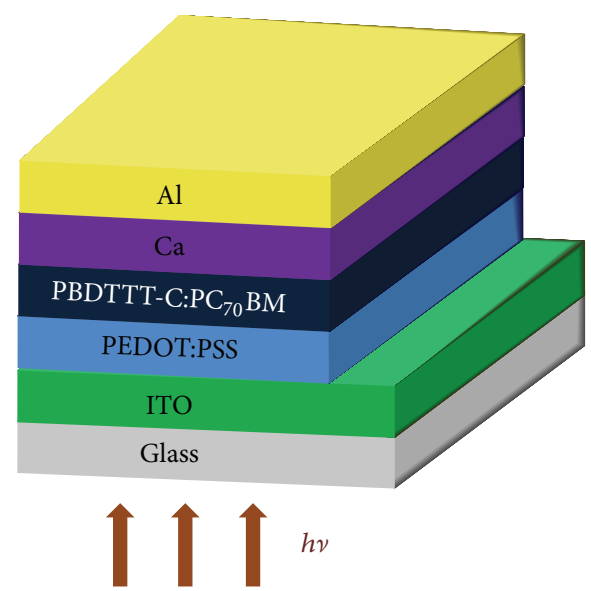

(c)

Figure 1: (a) Molecular structures of PBDTTT-C and PC ${ }_{70}$ BM. (b) The structure of the inverted polymer solar cell. (c) The structure of the conventional polymer solar cell.

98.0-101.0\%) in $0.3 \mathrm{~mol}$ ethanolamine $\left(\mathrm{HOCH}_{2} \mathrm{CH}_{2} \mathrm{NH}_{2}\right.$, ACS, 99+\%) and 2-methoxyethanol $\left(\mathrm{C}_{3} \mathrm{H}_{8} \mathrm{O}_{2}\right.$, ACS, 99.3\%). PBDTTT-C (molecular weight: $>20,000 \mathrm{~g} / \mathrm{mol}$ and PDI: 1.8-2.5) was purchased from Solarmer Materials Inc, and $\mathrm{PC}_{70} \mathrm{BM}$ was purchased from Solenne b.v. The corresponding chemical structures are depicted in Figure 1(a). 1, 8Diiodooctane (DIO) was purchased from Alfa Aesar. Poly (3, 4-ethylenedioxylenethiophene) : poly (styrenesulphonic acid) (PEDOT : PSS) (Clevious P VP AI 4083) was purchased from H. C. Starck Company.

2.2. Fabrication of Solar Cells. Inverted PSCs were fabricated with the structure of glass/ITO/ZnO/PBDTTT$\mathrm{C}: \mathrm{PC}_{70} \mathrm{BM} / \mathrm{MoO}_{3} / \mathrm{Ag}$ (Figure $1(\mathrm{~b})$ ). ITO glasses were cleaned with detergent, deionized water, acetone, and isopropanol and subsequently dried with $\mathrm{N}_{2}$ flow. $\mathrm{ZnO}$ films were prepared by spin coating from the $\mathrm{ZnO}$ precursor solution at a speed of $4000 \mathrm{rpm}$ for $50 \mathrm{~s}$ and baked at $150^{\circ} \mathrm{C}$ for $5 \mathrm{~min}$ at ambient air. Then the organic residues in the $\mathrm{ZnO}$ film were removed by ultrasonic cleaning in deionized water, acetone, and isopropyl alcohol. The active layer was then prepared by spin coating from dichlorobenzene solution of PBDTTT-C and $\mathrm{PC}_{70} \mathrm{BM}(1: 1.5 \mathrm{w} / \mathrm{w}$, polymer concentration of $10 \mathrm{mg} / \mathrm{mL}$ ) with $3 \%$ volume ratio of DIO additive on $\mathrm{ZnO}$ films with thickness of $\sim 80 \mathrm{~nm}$ in a nitrogen-filled glove box. Finally, $15 \mathrm{~nm} \mathrm{MoO}_{3}$ and $100 \mathrm{~nm}$ Ag were thermally deposited on the active layer under the pressure of $4 \times 10^{-4} \mathrm{~Pa}$. The active area of the device was $4.5 \mathrm{~mm}^{2}$.

Conventional PSCs were fabricated with the structure of glass/ITO/PEDOT : PSS/PBDTTT-C : $\mathrm{PC}_{70} \mathrm{BM} / \mathrm{Ca} / \mathrm{Al}$ (Figure 1(c)). The precleaned ITO substrates were treated with UV-ozone for $20 \mathrm{~min}$, then modified by spin-coating PEDOT:PSS with a thickness of around $40 \mathrm{~nm}$, and then baked at $150^{\circ} \mathrm{C}$ for 15 minutes at ambient conditions. Then 


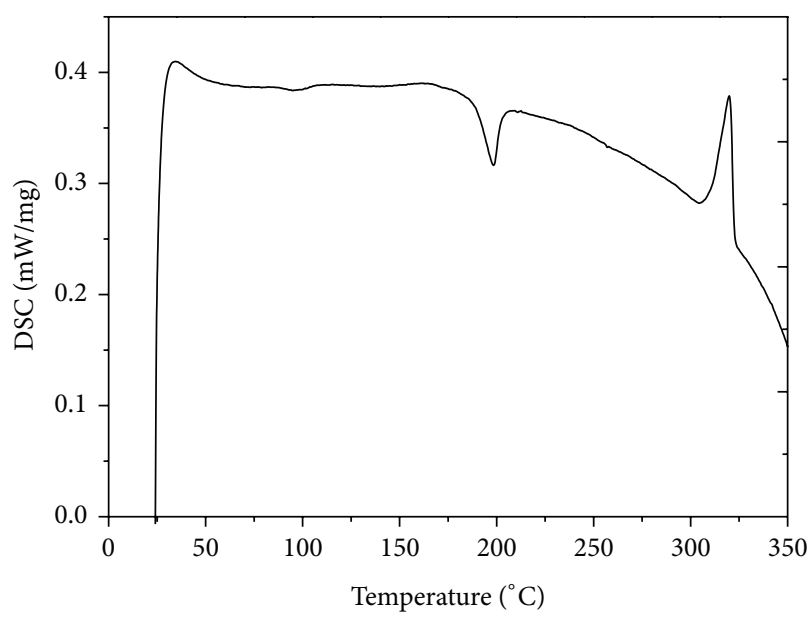

- PCBM

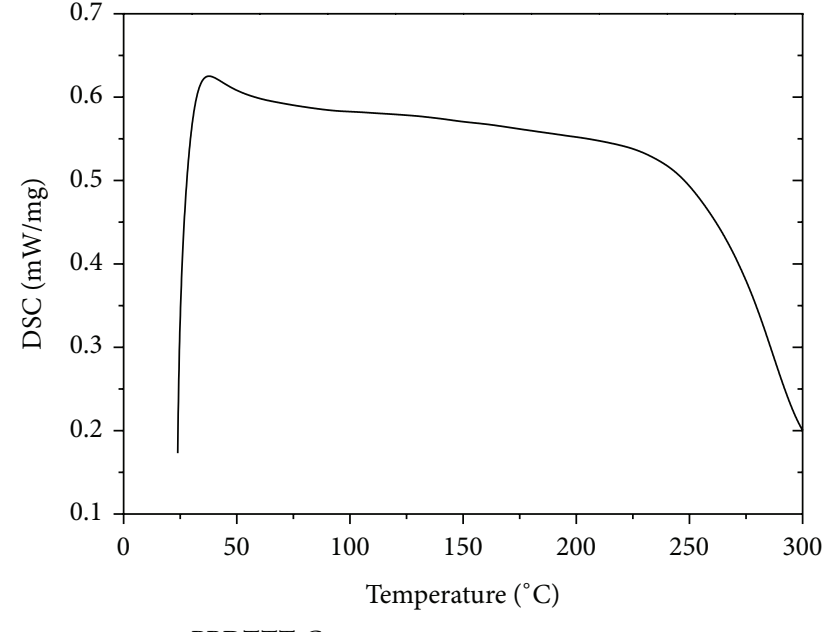

(b)

(a)

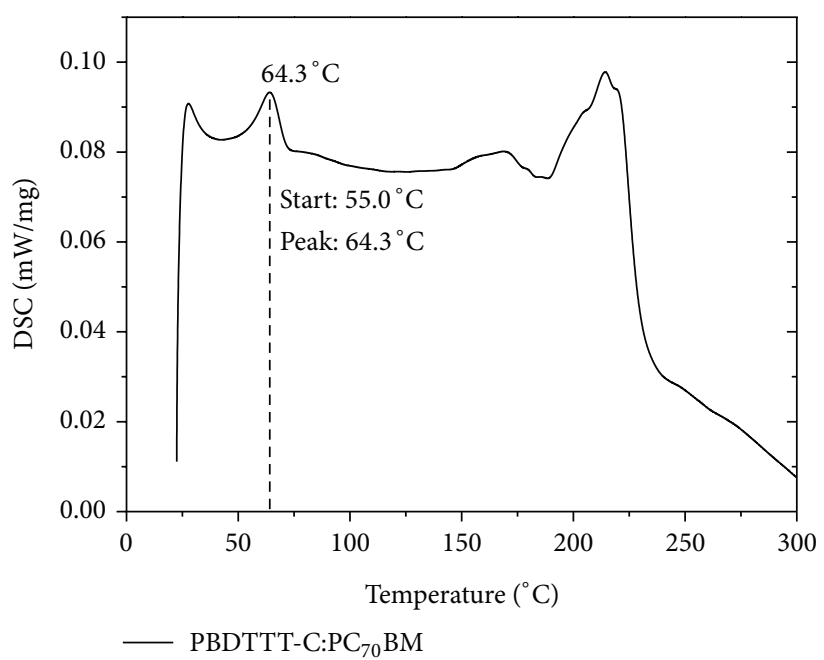

(c)

FIGURE 2: DSC thermograms showing the heating processes for the pure $\mathrm{PC}_{70} \mathrm{BM}(\mathrm{a})$, pure PBDTTT-C (b), and PBDTTT-C/PC ${ }_{70} \mathrm{BM}$ blends (c).

TABLE 1: Device parameters of the conventional and inverted devices which are kept at $70^{\circ} \mathrm{C}$ for different time.

\begin{tabular}{|c|c|c|c|c|c|}
\hline Device structures & Time (h) & $\mathrm{Jsc}\left(\mathrm{mA} / \mathrm{cm}^{2}\right)$ & $\operatorname{Voc}(\mathrm{V})$ & FF (\%) & PCE (\%) \\
\hline \multirow{6}{*}{ Conventional } & Control & 15.41 & 0.71 & 60.56 & 6.62 \\
\hline & 1 & 14.91 & 0.71 & 58.34 & 6.17 \\
\hline & 2 & 14.79 & 0.70 & 58.99 & 6.11 \\
\hline & 3 & 14.77 & 0.71 & 57.94 & 6.07 \\
\hline & 5 & 14.37 & 0.71 & 58.97 & 6.01 \\
\hline & 18 & 13.71 & 0.72 & 58.38 & 5.76 \\
\hline \multirow{6}{*}{ Inverted } & Control & 15.28 & 0.72 & 61.33 & 6.74 \\
\hline & 1 & 15.12 & 0.72 & 61.40 & 6.68 \\
\hline & 2 & 14.66 & 0.71 & 62.64 & 6.52 \\
\hline & 3 & 14.64 & 0.71 & 62.37 & 6.48 \\
\hline & 5 & 14.59 & 0.71 & 62.46 & 6.47 \\
\hline & 18 & 13.86 & 0.71 & 62.08 & 6.11 \\
\hline
\end{tabular}




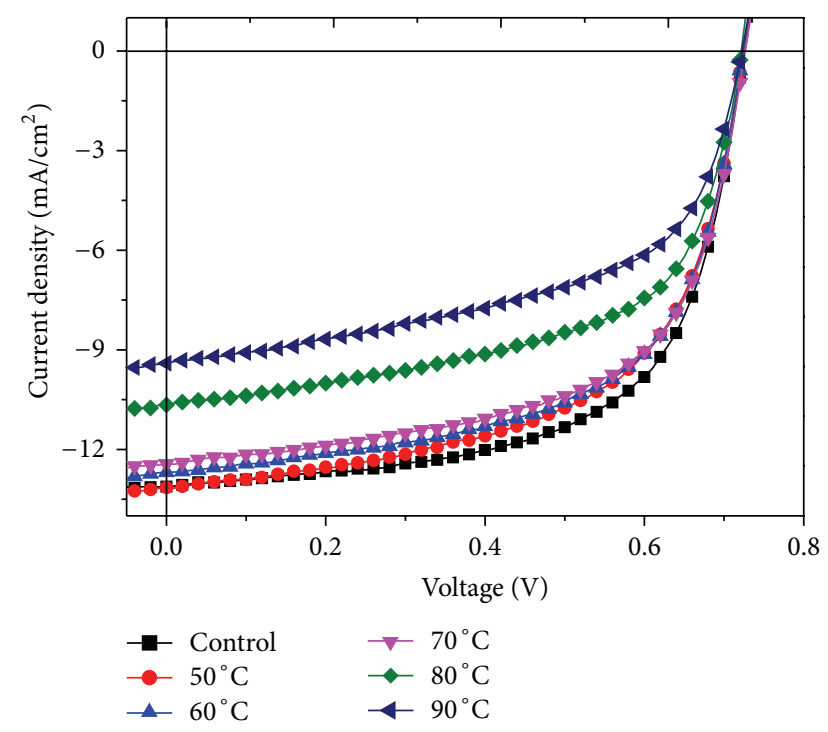

FIGURE 3: $J-V$ curves of the inverted solar cells treated at different temperatures.

the substrates with PEDOT: PSS were transferred to glove box to fabricate the photoactive layer at experiment condition similar to those in the inverted device. Finally, $20 \mathrm{~nm}$ Ca and $100 \mathrm{~nm}$ Al were thermally deposited on the active layer as cathodes.

2.3. Device Characterizations. The current density-voltage $(J-V)$ measurements of the devices were performed by a computer-controlled Keithley 6430 Source Measure Unit. Photovoltaic characterization was conducted under simulated AM1.5G irradiation $\left(100 \mathrm{~mW} / \mathrm{cm}^{2}\right)$ of solar simulator XES-301S+EL-100 (SAN-EI ELECTRIC). The thermalstability tests were carried out on a hotplate (IKA RCT basic magnetic stirrer) as heating source to control temperature at an accuracy of $\pm 1^{\circ} \mathrm{C}$. All electrical measurements were performed in a nitrogen-filled glove box. A UV/visible spectrophotometer (Shimadzu UV-3101) was used to characterize the absorption properties of the PBDTTT-C: $\mathrm{PC}_{70} \mathrm{BM}$ layer. TEM images were obtained by using a Tecnai G2 F30 transmission electron microscope operated at $300 \mathrm{kV}$.

PBDTTT-C and $\mathrm{PC}_{70} \mathrm{BM}$ spin-coated on glass substrate were collected for differential scanning calorimetry (DSC) measurements, which were performed on a NETZSCH DSC 200F3 equipment. $\mathrm{N}_{2}$ (flux about $60 \mathrm{~mL} / \mathrm{min}$ ) was used as the purge gas. Approximately $5 \mathrm{mg}$ of the samples was sealed in perforated aluminum crucibles. The scan rate during DSC measurements was set to $5 \mathrm{~K} / \mathrm{min}$.

To measure transient photoconductivity, the samples were excited by an optical parametric oscillator (OPO) pumped by a Q-switched neodymium ion-doped yttrium aluminum garnet $\left(\mathrm{Nd}^{3+}: \mathrm{YAG}\right)$ laser. The OPO delivered pulses with a duration of about $5 \mathrm{~ns}$, a wavelength of $460 \mathrm{~nm}$, and an energy of $3 \mathrm{~nJ}$ per pulse at a repetition rate of $10 \mathrm{~Hz}$. The carriers of the devices were generated by a short laser pulse; then the transient photocurrent was obtained by measuring the voltage drop across a $5 \Omega$ resistor load that was connected in series with the solar cell; the current traces were recorded by a Tektronix TDS 540D oscilloscope.

\section{Results and Discussion}

High temperatures can accelerate PSCs degradation [16]. The Arrhenius model describes this process [17], in which the degradation constant is defined as follows:

$$
k_{\mathrm{deg}}=A \exp \left(\frac{-E_{a}}{k_{B} T}\right) \text {, }
$$

where $E_{a}$ is the activation energy, $k_{B}$ is the Boltzmann constant, $T$ is the temperature $(\mathrm{K})$, and $A$ is a constant dependent on the degradation mechanisms and the experimental conditions. Typically, degradation process is in close association with the intrinsic properties of materials, such as the trapping behavior of electrical carriers and structural and chemical changes of polymers. The activation energy $E_{a}$ is a common parameter that the activated processes have to overcome. Hence, the kinetic processes are strongly temperature dependent.

Hou et al. reported that the glass transition temperature of PBDTTT-C is about $400^{\circ} \mathrm{C}$ to $410^{\circ} \mathrm{C}$, which is above the operating temperature of the device [18]. In this study, the thermal behavior of PBDTTT-C, $\mathrm{PC}_{70} \mathrm{BM}$, and their blends is investigated by DSC to determine the temperature of phase transitions. The traces of heat flow during the annealing of PBDTTT-C, $\mathrm{PC}_{70} \mathrm{BM}$, and their blends are illustrated in Figure 2. For pure $\mathrm{PC}_{70} \mathrm{BM}$, an exothermic peak $\left(197^{\circ} \mathrm{C}\right)$ and a melting peak $\left(204^{\circ} \mathrm{C}\right)$ are observed in Figure $2(\mathrm{a})$. From Figure 2(c), we can find a new distinguishable peak locating at $64.3^{\circ} \mathrm{C}$ defined as the eutectic temperature of the blend of PBDTTT-C and $\mathrm{PC}_{70} \mathrm{BM}$. The new peak corresponds to the melting temperature of bimolecular crystals formed by fullerene intercalation between the polymer side chains [19, 20]. The well-ordered bimolecular crystals can cause strong charge-transfer states due to the strong coupling of the dissimilar nearest neighbor molecules $[20,21]$. So the reduction of bimolecular crystals would affect the electronic properties of the PSCs such as exciton dissociation, recombination, and charge transport.

Considering our DSC results and the actual working temperature of the solar cells in outdoor environments (in the range of $30^{\circ} \mathrm{C}$ to $80^{\circ} \mathrm{C}$ ), the temperature ranging from $50^{\circ} \mathrm{C}$ to $90^{\circ} \mathrm{C}$ was selected to investigate PSCs degradation. All measurements were performed in a glove box to avoid oxygen and water induced degradation. Figure 3 reveals that the performance of devices exhibits burn-in losses under thermal stress at different temperatures for $1 \mathrm{~h}$. The open-circuit voltage (Voc) is stable at $0.72 \mathrm{~V}$, and the short-circuit current density (Jsc) acts as the major degradation factor. The heated devices display a slightly decline in Jsc compared with the control device when the temperature is below $70^{\circ} \mathrm{C}$. However, Jsc shows a steep decrease at $80^{\circ} \mathrm{C}$ and $90^{\circ} \mathrm{C}$. The decrease of the Jsc means the reduced interfacial area between the donor polymer and the acceptor fullerene after the annealing [22]. Integrating the results of DSC measurements, we selected 


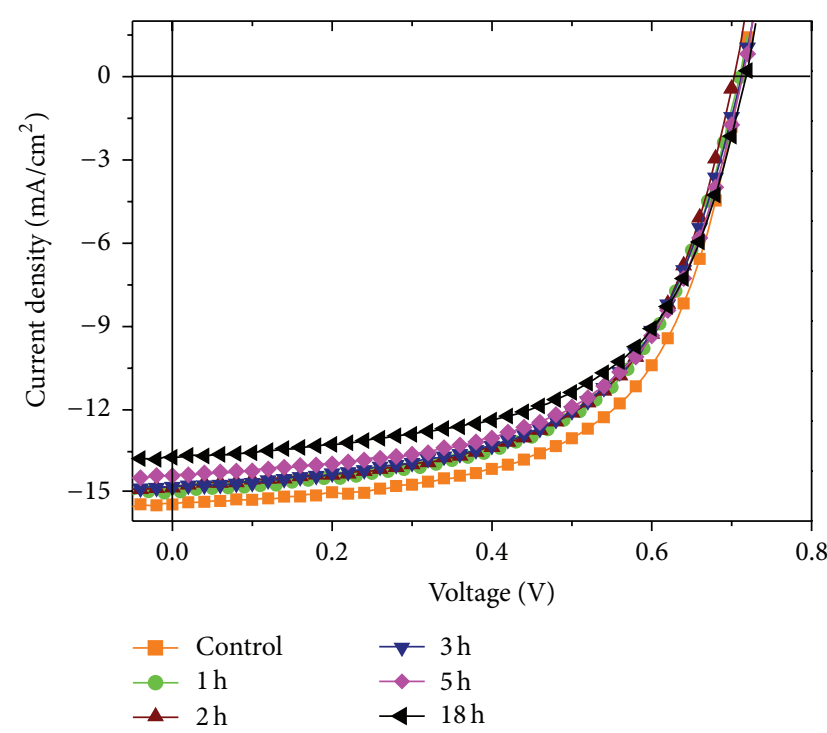

(a)

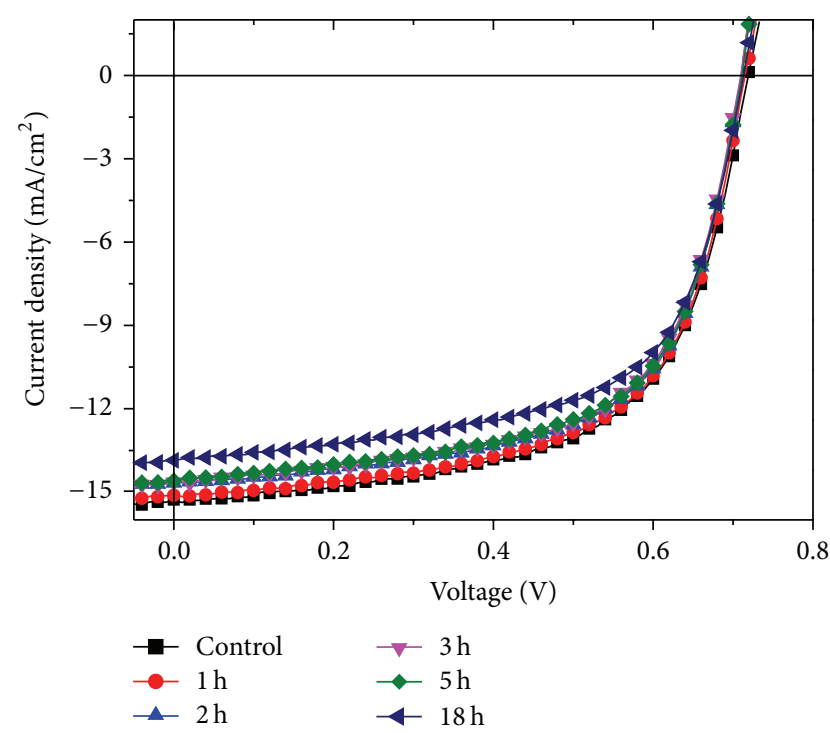

(b)

Figure 4: $J$ - $V$ curves of the (a) conventional and (b) inverted solar cells treated at $70^{\circ} \mathrm{C}$ for different time.

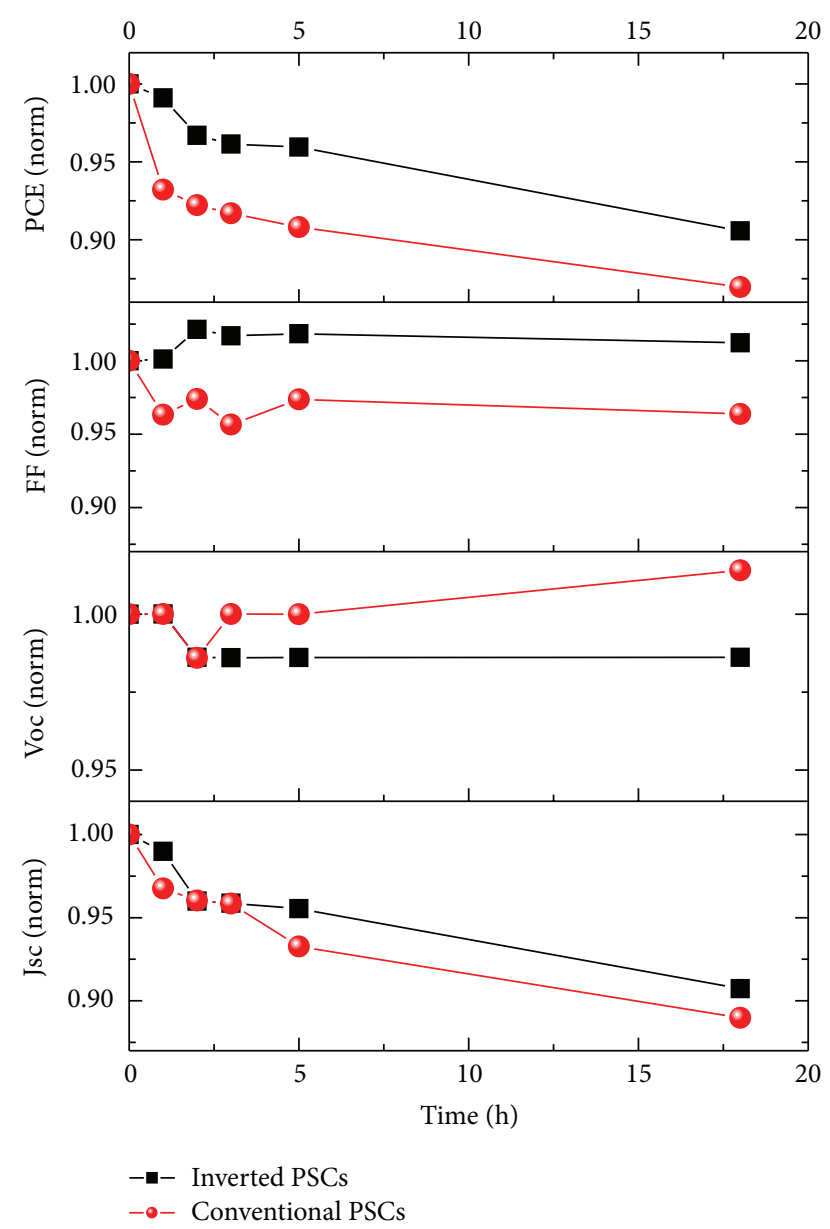

FIgURE 5: Normalized PCE, FF, Voc, and Jsc of conventional (red dot) and inverted (black square) solar cells at $70^{\circ} \mathrm{C}$ for different time. All curves are normalized to the initial value. $70^{\circ} \mathrm{C}$ as the actual condition temperature to analyze the effects of heating duration on the long-term performances of PSCs.

The $J-V$ characteristics of PSCs are shown in Figure 4, and the performance of the devices is summarized in Table 1. The conventional and inverted devices exhibit significantly reduced performances after heat treatment at $70^{\circ} \mathrm{C}$ for $18 \mathrm{~h}$. For conventional devices, efficiency decreases from $6.62 \%$ to $5.76 \%$, Jsc decreases from $15.29 \mathrm{~mA} / \mathrm{cm}^{2}$ to $14.76 \mathrm{~mA} / \mathrm{cm}^{2}$, and fill factor (FF) drops from $60.56 \%$ to $58.28 \%$. For inverted devices, Jsc decreases from $15.28 \mathrm{~mA} / \mathrm{cm}^{2}$ to $13.86 \mathrm{~mA} / \mathrm{cm}^{2}$, and $\mathrm{FF}$ increases to a maximum value of $62.64 \%$ after $2 \mathrm{~h}$ heating treatment and then slightly decreases to $62.08 \%$. Variations in the parameters result in PCE degradation from $6.74 \%$ to $6.11 \%$. To further compare the photovoltaic performances of conventional and inverted PSCs, the normalized PCE, FF, Voc, and Jsc are shown in Figure 5. Jsc of the conventional devices is degraded by $11 \%$, which is slightly higher than that of the inverted devices (9\%). Although Voc and FF of both PSCs fluctuate during heating, inverted PSCs exhibit a more stable FF value. PCE of the inverted PSCs decreases by $10 \%$, whereas that of the conventional devices drops to $85 \%$ of the original PCE during $18 \mathrm{~h}$ thermal treatment. The better thermal stability of the inverted PSCs may be attributed to the natural self-encapsulated structure that comprised a well vertical phase separation in the active layer $[23,24]$, on which the metal oxides $\left(\mathrm{MoO}_{3}\right)$ and stable metals (Ag) are deposited as the buffer layer and top electrode, respectively $[25,26]$. Considering that the inverted PSCs have better thermal stability than that of the conventional PSCs, we choose the inverted PSCs as the study object in the following discussion.

In general, Jsc is determined by the generation, transport, and extraction of charge carriers. Reduction in this parameter is larger than that of the other parameters during the 


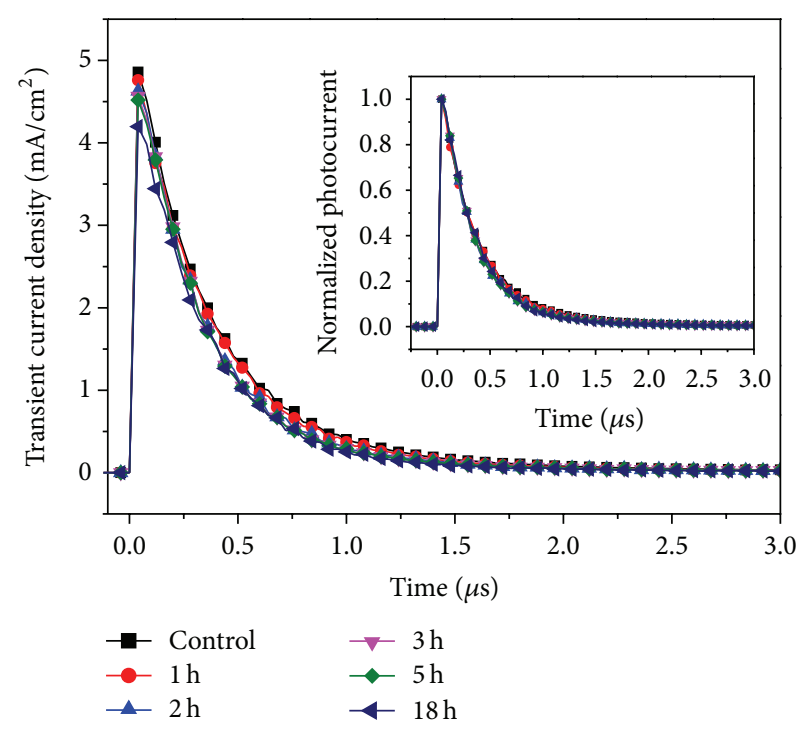

(a)

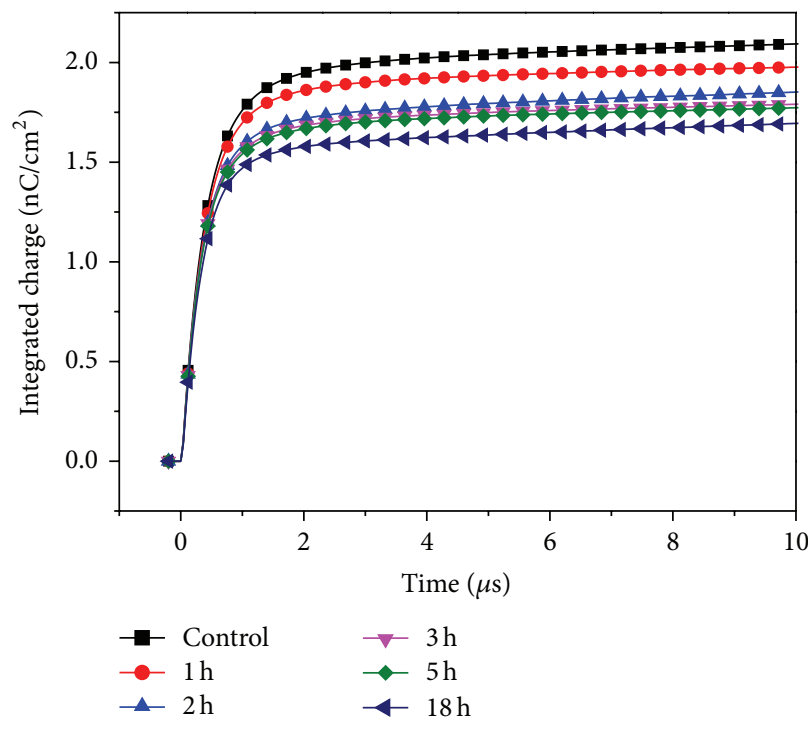

(b)

FIGURE 6: (a) Decay of the transient photocurrent density $J$ and normalized $J$ (insert) of control device and the devices thermally treated at $70^{\circ} \mathrm{C}$ for different time. (b) Total swept-out charge density as a function of decay time for solar cells.

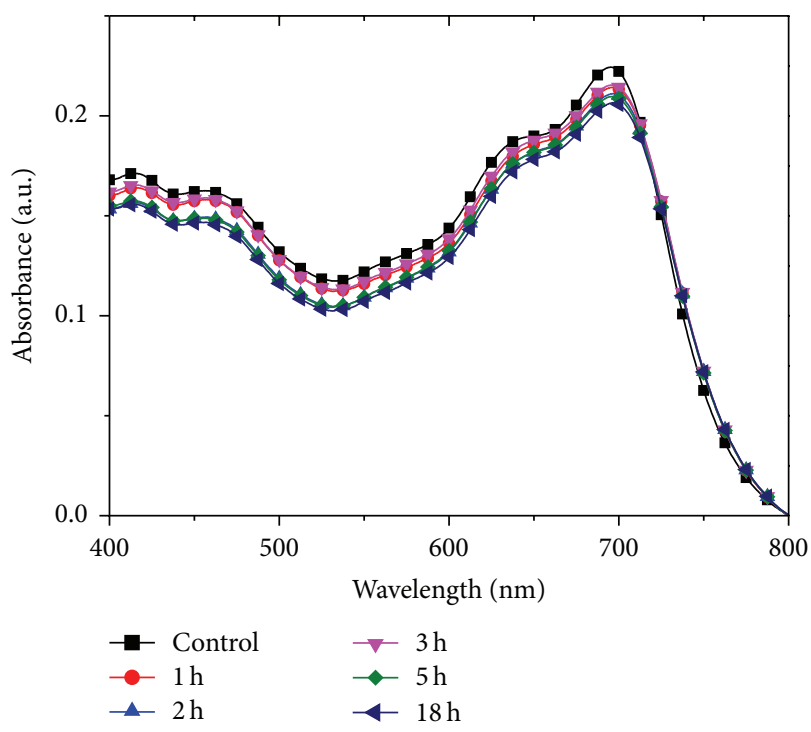

(a)

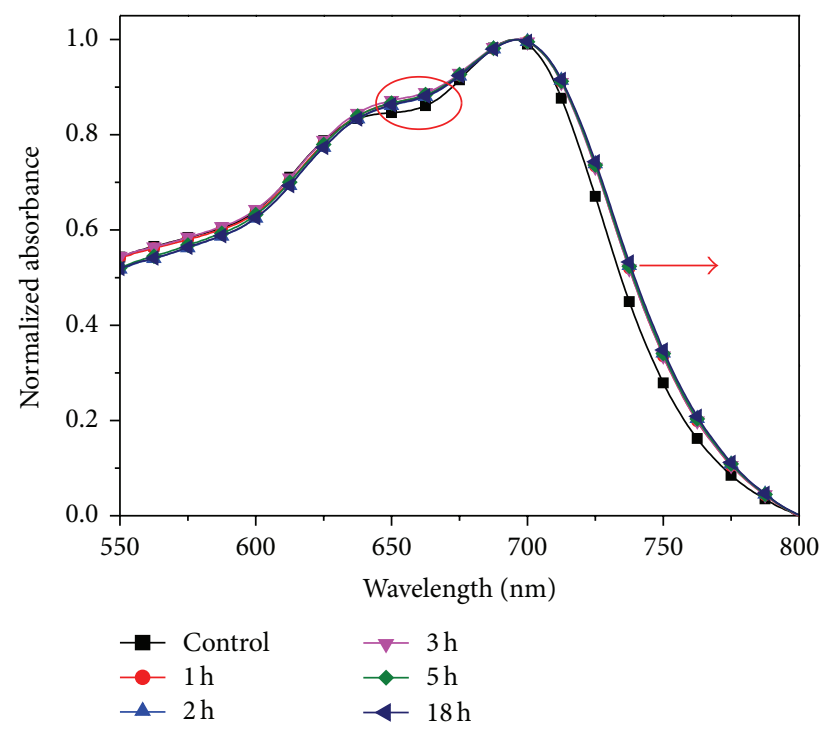

(b)

Figure 7: Absorption spectra of the (a) inverted solar cells and the normalized absorption spectra of (b) inverted solar cells treated at $70^{\circ} \mathrm{C}$ for different time.

prolonged heating. The transient photocurrent is measured to investigate the influence of thermal treatment on charge transport kinetics [27]. The transient photoconductivity of the inverted devices treated with different heating times is shown in Figure 6. As shown in the inset of Figure 6(a), the transient photocurrent curves of devices reflect the rates of the extracted carriers in the BHJ active layer, which could result in the change of the FF values. The temporal dependence of the total swept-out charge density calculated by integrating the photocurrent decay is shown in Figure 6(b). The total charges of the PSCs after thermal treatment significantly decreased compared with those of the control devices. The number of mobile carriers constantly decreases with increasing heating time.

The extraction of photogeneration charges is low because of the reduced absorption with prolonged heating time [28]. To further study the photogeneration charges of the PSCs after thermal treatment, the corresponding absorption spectra were measured (Figure 7). The absorption intensity of inverted PSCs decreases with increasing heating time because of the unstable morphological evolution (Figure 7(a)). This evolution leads to the excessive phase separation in the 


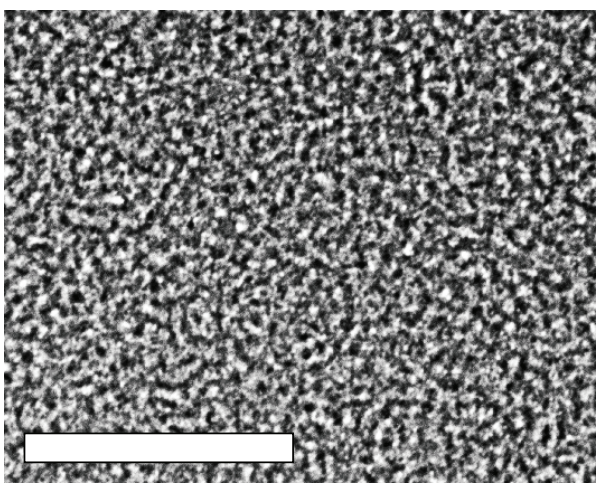

(a)

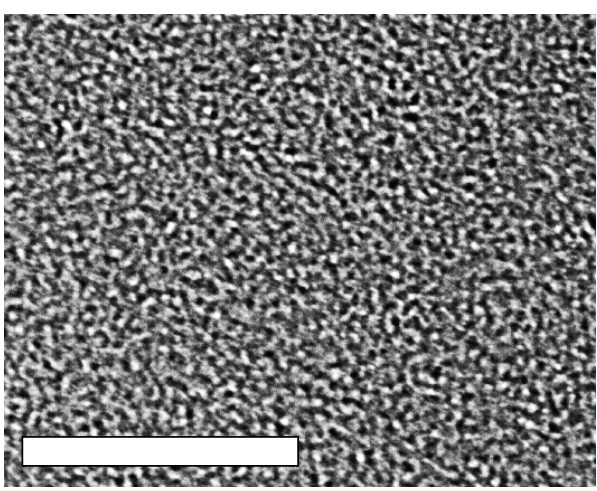

(c)

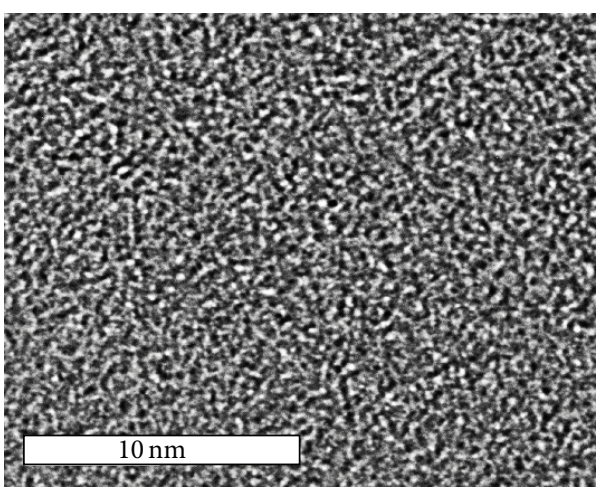

(e)

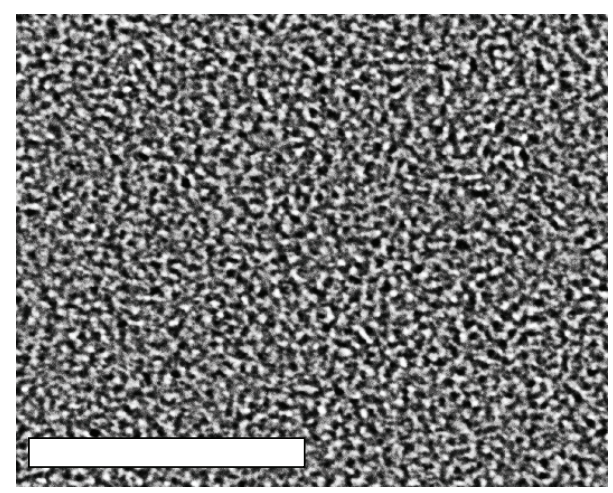

(b)

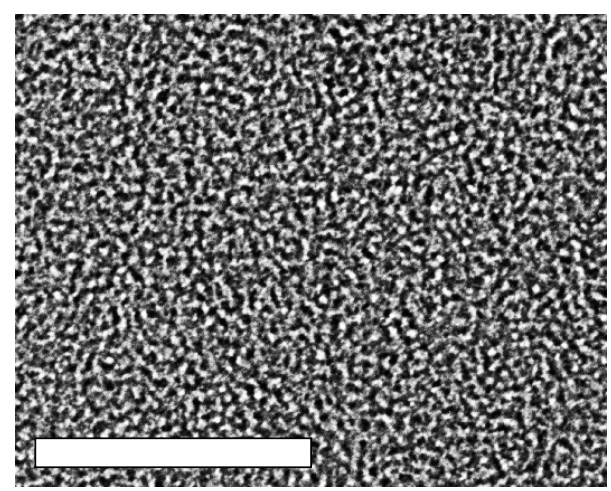

(d)

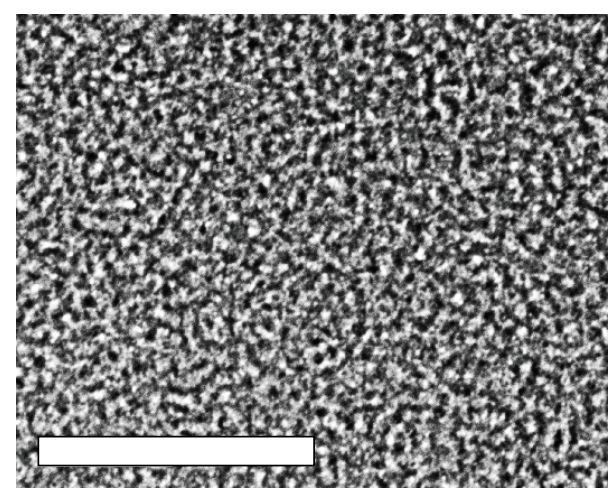

(f)

Figure 8: TEM images of the PBDTTT-C: $\mathrm{PC}_{70} \mathrm{BM}$ films treated at $70^{\circ} \mathrm{C}$ for control (a), 1 hour (b), 2 hours (c), 3 hours (d), 5 hours (e), and 18 hours (f).

blend films. The absorption of PSCs increases from $650 \mathrm{~nm}$ to $670 \mathrm{~nm}$ with the heating time after thermal treatment based on the normalized absorption spectra (Figure 7(b)). The absorption maximum exhibits a redshift with increasing heating time, which indicates that the high crystalline order and large domain sizes are obtained during the thermal process. The charge-carrier transport is unbalanced because of the uneven crystalline state (Figure 6) $[29,30]$.

TEM images of the blend films which are obtained before and after thermal treatment are given in Figure 8. The ascasted blend film exhibits a well-developed phase separation with the PBDTTT-C and the $\mathrm{PC}_{70} \mathrm{BM}$ uniformly distributed across the network of the blend film and donor-acceptor domains with appropriate sizes (Figure 8(a)). The outlines of the phase separation between PBDTTT-C and $\mathrm{PC}_{70} \mathrm{BM}$ are very clear as shown in Figure 8(a). The interpenetrating networks with appropriate phase sizes can provide a favorable interface for exciton dissociation and pathways for chargecarrier transport without too many chances of recombination during the transit processes $[16,22]$. The distribution of the donor-acceptor phases becomes more compact, when the heating time is increased from $1 \mathrm{~h}$ to $5 \mathrm{~h}$ (Figure $8(\mathrm{~b})$ to Figure $8(\mathrm{e}))$. It means that the clusters of the $\mathrm{PC}_{70} \mathrm{BM}$ have grown with big sizes by the incorporating molecules drawn from the distributed $\mathrm{PC}_{70} \mathrm{BM}$ network. Subsequently, the states of the domains become ambiguous. With the growing 
numbers and sizes, the clusters touch each other and deplete the polymer matrix due to lack of space. The outlines of the phase separation between the $\mathrm{PC}_{70} \mathrm{BM}$ and PBDTTT$\mathrm{C}$ appear to be blurry. The TEM image of the blend film reveals the phase separation with large domain size after $18 \mathrm{~h}$ thermal treatment, which changes the absorption, exciton dissociation, and carriers transport.

\section{Conclusion}

In summary, the effects of heating temperature and heating time on the thermal stability of conventional and inverted PSCs based on PBDTTT-C: $\mathrm{PC}_{70} \mathrm{BM}$ in a $\mathrm{N}_{2}$ atmosphere are analyzed. The results reveal that the inverted PSCs exhibit better thermal stability than the conventional devices. The absorption of the blend film decreases with increasing heating time because of the formation of high crystalline orders and large domain sizes. Transient photoconductivity results indicate that the inefficient charge generation and nonequilibrium charge-carrier transport may result in the thermal degradation of PSCs. These results provide methods to enhance the thermal stability of the PSCs.

\section{Conflict of Interests}

The authors declare that there is no conflict of interests regarding the publication of this paper.

\section{Acknowledgments}

This research is supported by the Natural Science Foundation of China (Grant nos. 61275175, 61177017, and 61377028), the National Science Foundation for Distinguished Young Scholars of China (Grant no. 61125505), and the Fundamental Research Funds for the Central University (2014JBZ009).

\section{References}

[1] Z. He, C. Zhong, X. Huang et al., "Simultaneous enhancement of open-circuit voltage, short-circuit current density, and fill factor in polymer solar cells," Advanced Materials, vol. 23, no. 40, pp. 4636-4643, 2011.

[2] Q. Lu, Z. Lu, Y. Lu et al., "Photocatalytic synthesis and photovoltaic application of Ag-TiO2 nanorod composites," Nano Letters, vol. 13, no. 11, pp. 5698-5702, 2013.

[3] Z. He, C. Zhong, S. Su, M. Xu, H. Wu, and Y. Cao, "Enhanced power-conversion efficiency in polymer solar cells using an inverted device structure," Nature Photonics, vol. 6, no. 9, pp. 591-595, 2012.

[4] J. You, L. Dou, K. Yoshimura et al., "A polymer tandem solar cell with $10.6 \%$ power conversion efficiency," Nature Communications, vol. 4, article 1446, 2013.

[5] M. Jørgensen, K. Norrman, and F. C. Krebs, "Stability/degradation of polymer solar cells," Solar Energy Materials and Solar Cells, vol. 92, no. 7, pp. 686-714, 2008.

[6] M. Jørgensen, K. Norrman, S. A. Gevorgyan, T. Tromholt, B. Andreasen, and F. C. Krebs, "Stability of polymer solar cells," Advanced Materials, vol. 24, no. 5, pp. 580-612, 2012.
[7] C. H. Peters, I. T. Sachs-Quintana, J. P. Kastrop, S. Beaupré, M. Leclerc, and M. D. McGehee, "High efficiency polymer solar cells with long operating lifetimes," Advanced Energy Materials, vol. 1, no. 4, pp. 491-494, 2011.

[8] C. H. Peters, I. T. Sachs-Quintana, W. R. Mateker et al., "The mechanism of burn-in loss in a high efficiency polymer solar cell," Advanced Materials, vol. 24, no. 5, pp. 663-668, 2012.

[9] M. T. Lloyd, D. C. Olson, P. Lu et al., "Impact of contact evolution on the shelf life of organic solar cells," Journal of Materials Chemistry, vol. 19, no. 41, pp. 7638-7642, 2009.

[10] F. C. Krebs and K. Norrman, "Analysis of the failure mechanism for a stable organic photovoltaic during $10000 \mathrm{~h}$ of testing," Progress in Photovoltaics: Research and Applications, vol. 15, no. 8, pp. 697-712, 2007.

[11] M. Manceau, E. Bundgaard, J. E. Carlé et al., "Photochemical stability of $\pi$-conjugated polymers for polymer solar cells: a rule of thumb," Journal of Materials Chemistry, vol. 21, no. 12, pp. 4132-4141, 2011.

[12] M. O. Reese, A. M. Nardes, B. L. Rupert et al., "Photoinduced degradation of polymer and polymer-fullerene active layers: experiment and theory," Advanced Functional Materials, vol. 20, no. 20, pp. 3476-3483, 2010.

[13] M. Manceau, A. Rivaton, J.-L. Gardette, S. Guillerez, and N. Lemaitre, "The mechanism of photo- and thermooxidation of poly(3-hexylthiophene) (P3HT) reconsidered," Polymer Degradation and Stability, vol. 94, no. 6, pp. 898-907, 2009.

[14] A. Rivaton, S. Chambon, M. Manceau, J. Gardette, N. Lemaître, and S. Guillerez, "Light-induced degradation of the active layer of polymer-based solar cells," Polymer Degradation and Stability, vol. 95, no. 3, pp. 278-284, 2010.

[15] H. C. Wong, Z. Li, C. H. Tan et al., "Morphological stability and performance of polymer-fullerene solar cells under thermal stress: the impact of photoinduced PC60BM oligomerization," ACS Nano, vol. 8, pp. 1297-1308, 2014.

[16] B. Conings, S. Bertho, K. Vandewal et al., "Modeling the temperature induced degradation kinetics of the short circuit current in organic bulk heterojunction solar cells," Applied Physics Letters, vol. 96, no. 16, Article ID 163301, 2010.

[17] S. Schuller, P. Schilinsky, J. Hauch, and C. J. Brabec, "Determination of the degradation constant of bulk heterojunction solar cells by accelerated lifetime measurements," Applied Physics A, vol. 79, no. 1, pp. 37-40, 2004.

[18] J. Hou, H.-Y. Chen, S. Zhang et al., "Synthesis of a low band gap polymer and its application in highly efficient polymer solar cells," Journal of the American Chemical Society, vol. 131, no. 43, pp. 15586-15587, 2009.

[19] N. C. Miller, R. Gysel, C. E. Miller et al., "The phase behavior of a polymer-fullerene bulk heterojunction system that contains bimolecular crystals," Journal of Polymer Science B: Polymer Physics, vol. 49, no. 7, pp. 499-503, 2011.

[20] A. C. Mayer, M. F. Toney, S. R. Scully et al., "Bimolecular crystals of fullerenes in conjugated polymers and the implications of molecular mixing for solar cells," Advanced Functional Materials, vol. 19, no. 8, pp. 1173-1179, 2009.

[21] N. C. Cates, R. Gysel, Z. Beiley et al., "Tuning the properties of polymer bulk heterojunction solar cells by adjusting fullerene size to control intercalation," Nano Letters, vol. 9, no. 12, pp. 4153-4157, 2009.

[22] K. Maturová, S. S. van Bavel, M. M. Wienk, R. A. J. Janssen, and M. Kemerink, "Morphological device model for organic bulk heterojunction solar cells," Nano Letters, vol. 9, no. 8, pp. 30323037, 2009. 
[23] Z. Xu, L.-M. Chen, G. Yang et al., "Vertical phase separation in poly(3-hexylthiophene): Fullerene derivative blends and its advantage for inverted structure solar cells," Advanced Functional Materials, vol. 19, no. 8, pp. 1227-1234, 2009.

[24] M. Campoy-Quiles, T. Ferenczi, T. Agostinelli et al., "Morphology evolution via self-organization and lateral and vertical diffusion in polymer: fullerene solar cell blends," Nature Materials, vol. 7, no. 2, pp. 158-164, 2008.

[25] J. You, C.-C. Chen, L. Dou et al., "Metal oxide nanoparticles as an electron-transport layer in high-performance and stable inverted polymer solar cells," Advanced Materials, vol. 24, no. 38, pp. 5267-5272, 2012.

[26] K. Lee, J. Y. Kim, S. H. Park, S. H. Kim, S. Cho, and A. J. Heeger, "Air-stable polymer electronic devices," Advanced Materials, vol. 19, no. 18, pp. 2445-2449, 2007.

[27] Y. Zhang, H. Zhou, J. Seifter et al., "Molecular doping enhances photoconductivity in polymer bulk heterojunction solar cells," Advanced Materials, vol. 25, no. 48, pp. 7038-7044, 2013.

[28] J. Peet, M. L. Senatore, A. J. Heeger, and G. C. Bazan, "The role of processing in the fabrication and optimization of plastic solar cells," Advanced Materials, vol. 21, no. 14-15, pp. 1521-1527, 2009.

[29] X. Yang, J. K. J. Van Duren, R. A. J. Janssen, M. A. J. Michels, and J. Loos, "Morphology and thermal stability of the active layer in poly(p-phenylenevinylene)/methanofullerene plastic photovoltaic devices," Macromolecules, vol. 37, no. 6, pp. 21512158, 2004.

[30] J. K. J. van Duren, X. Yang, J. Loos et al., "Relating the morphology of poly(p-phenylene vinylene)/methanofullerene blends to solar-cell performance," Advanced Functional Materials, vol. 14, no. 5 , pp. 425-434, 2004. 

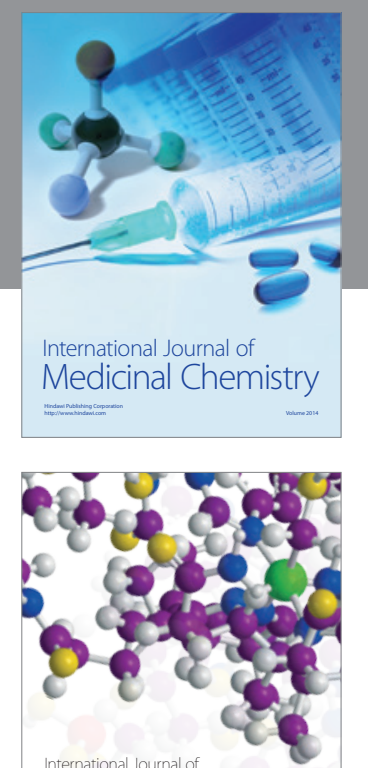

\section{Carbohydrate} Chemistry

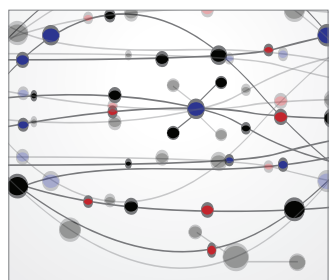

The Scientific World Journal
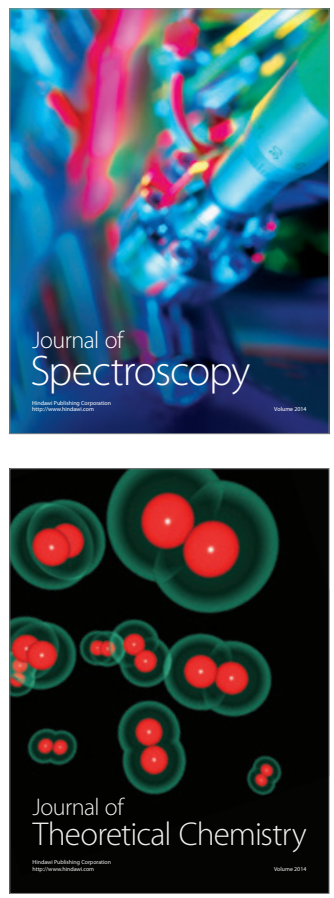
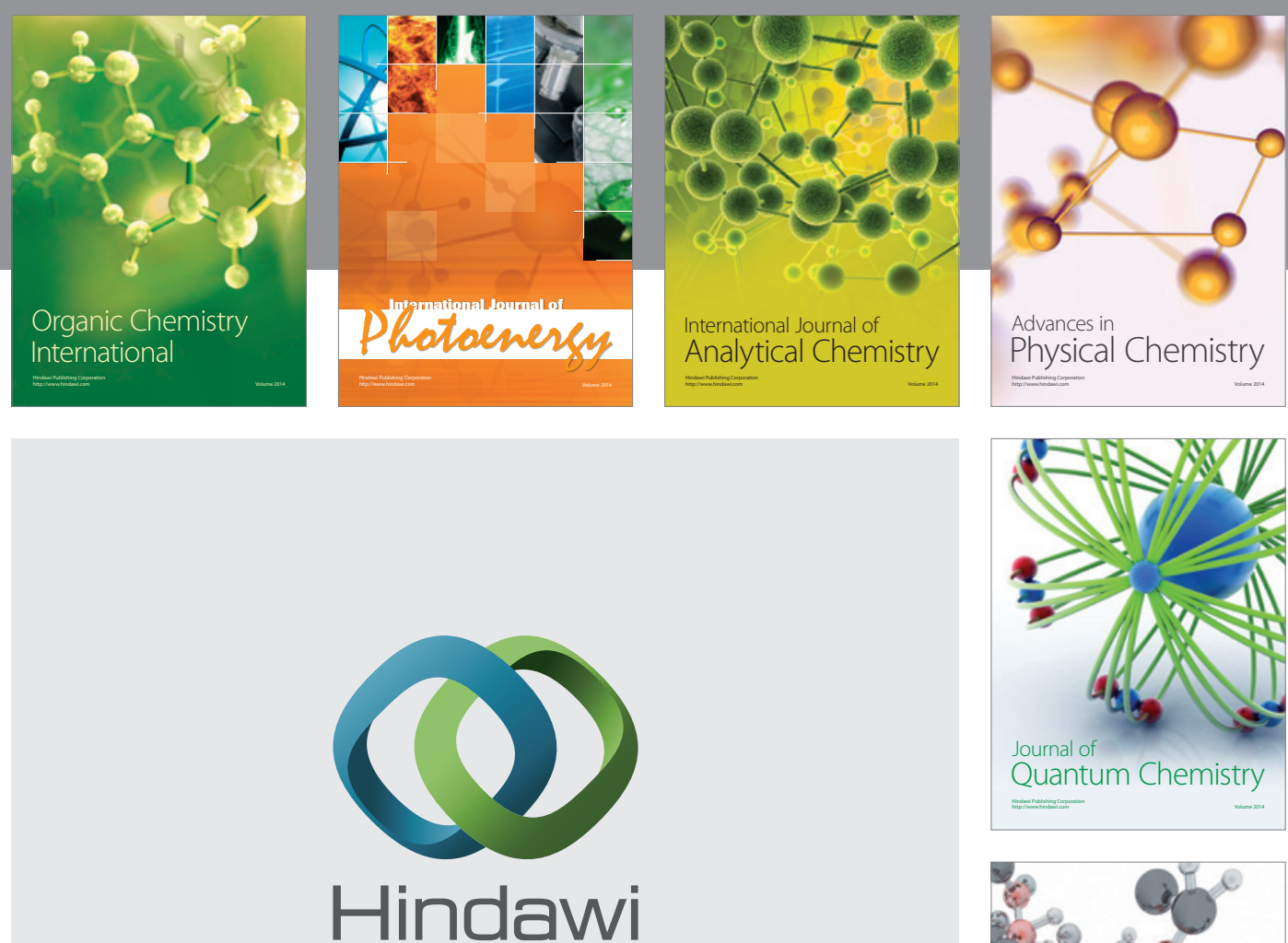

Submit your manuscripts at

http://www.hindawi.com

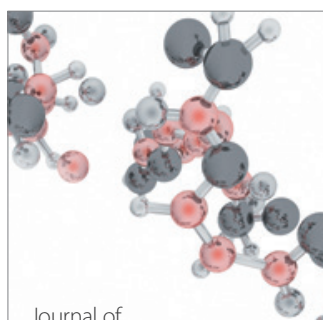

Analytical Methods

in Chemistry

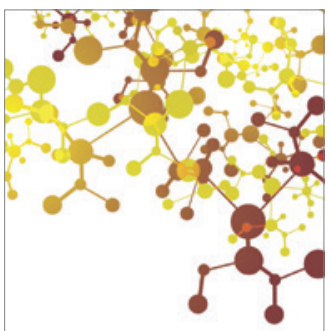

Journal of

Applied Chemistry

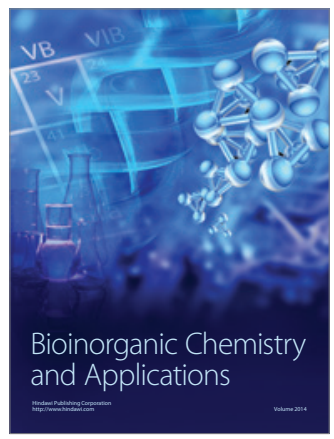

Inorganic Chemistry
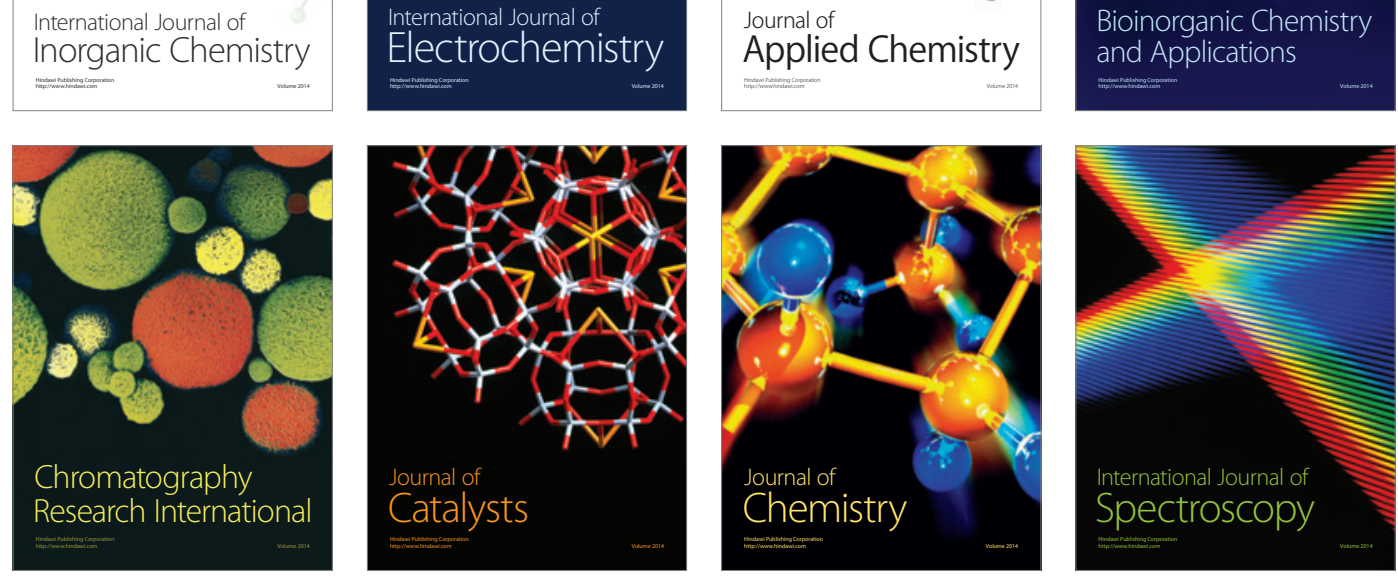